\title{
Biological Characterization of nef in Long-Term Survivors of Human Immunodeficiency Virus Type 1 Infection
}

\author{
YAOXING HUANG, LINQI ZHANG, AND DAVID D. HO* \\ Aaron Diamond AIDS Research Center, New York University \\ School of Medicine, New York, New York 10016
}

Received 8 June 1995/Accepted 28 August 1995

\begin{abstract}
We have previously shown that there were no gross deletions or obvious sequence abnormalities within nef of human immunodeficiency virus type 1 (HIV-1) in the 10 long-term survivors studied (Y. Huang, L. Zhang, and D. D. Ho, J. Virol. 69:93-100, 1995). Here we extend our study to examine these nef alleles in a functional context. Using a new technique, termed site-directed gene replacement, we have precisely replaced the nef of an infectious molecular clone, HIV-1 $1_{\mathrm{HXB} 2}$, with $n e f$ alleles derived from 10 long-term survivors as well as from a patient with AIDS. The replication properties of these chimeric viruses demonstrated that the nef alleles derived from long-term survivors neither significantly increased nor decreased viral replication, compared with the $n e f$ allele of $\mathrm{Nef}^{+} \mathrm{HIV}-1_{\mathrm{HXB} 2}$ and that derived from a patient with AIDS. However, Nef ${ }^{+}$viruses always replicated faster than virus lacking nef. Moreover, single-cell infection analysis by the MAGI assay showed that these chimeric viruses, as well as $\mathrm{Nef}^{+} \mathrm{HIV}_{-1} \mathbf{H X B 2}_{2}$, were more infectious than Nef ${ }^{-} \mathrm{HIV}-\mathbf{1}_{\mathrm{HXB} 2}$ was. Therefore, we conclude that the genotypic and phenotypic features of nef are not likely to account for the nonprogression of HIV-1 infection in the $\mathbf{1 0}$ cases studied, unless the function of the nef gene in vivo is not accurately reflected by the in vitro assays we used.
\end{abstract}

Following primary infection with human immunodeficiency virus type 1 (HIV-1), the majority of patients experience an extended asymptomatic period after seroconversion and prior to the development of AIDS, whereas some become immunosuppressed and develop opportunistic complications rapidly (1, 17). It has been estimated that the median time from the onset of HIV-1 infection to laboratory evidence of immunodeficiency is approximately 10 years (23). However, a small proportion of infected individuals remain clinically healthy and immunologically normal despite prolonged HIV-1 infection (2, 23 ). This group of patients constitutes approximately $5 \%$ of all HIV-1-infected individuals and has been termed long-term survivors or persons with long-term nonprogressive infection. Although the precise definition of long-term survivors of HIV-1 infection varies (23), these persons generally have been infected for over a decade, lack clinical symptoms, and maintain normal and stable $\mathrm{CD}^{+}{ }^{+}$-cell counts $(8,13,15,16,23$, 24).

Multiple host, viral, and environmental factors are believed to contribute to the spectrum of disease progression induced by HIV-1 infection (29). Host factors may result in differential susceptibility to viral infection and its pathogenic effects, whereas HIV-1 variation may account for differential virulence and disease course. Therefore, the sequelae of infection depend on the fine balance among these interactions. Although we have recently found strong HIV-1-neutralizing antibodies and virus-inhibitory $\mathrm{CD}^{+} \mathrm{T}$-cell responses in our cohort of long-term survivors, the kinetics of viral replication in two subjects (patients 7 and 8) clearly show the presence of an attenuated strain of HIV-1 (3). Additionally, the importance of viral load and phenotype in influencing the rate of disease progression to AIDS has become more evident recently (6, 9, $20,22,26,28)$. Two studies in particular strongly support the

\footnotetext{
* Corresponding author. Mailing address: Aaron Diamond AIDS Research Center, New York University School of Medicine, 455 First Ave., New York, NY 10016. Phone: (212) 725-0018. Fax: (212) 7251126. Electronic mail address: ho@adarc.nyu.edu.
}

notion that viral characteristics play a critical role in long-term nonprogression. First, an epidemiological observation made by Learmont et al. $(14,15)$ showed that seven transfusion recipients from an HIV-1-infected individual have remained clinically well and immunologically stable despite a decade of infection. Likewise, the blood donor has remained healthy. The existence of this cluster of long-term survivors raises the possibility that an attenuated virus strain of HIV-1 was transmitted. Second, experiments carried out by Kestler et al. (11) showed that monkeys experimentally inoculated with simian immunodeficiency virus from which nef had been deleted exhibited no sign of disease and maintained low viral burdens with normal CD $4^{+} \mathrm{T}$-cell counts. These characteristics are very similar to those seen in long-term survivors of HIV-1 infection, thereby prompting us to determine whether these long-term survivors are infected with viruses that are attenuated because of defects in Nef.

We previously demonstrated that most of the nef alleles derived from long-term survivors in our study were full length with an open reading frame (10), in contrast to one unique case reported by Kirchhoff et al. (13). At the protein level, there were no discernible differences between the Nef consensus sequences derived from our long-term survivors and those from patients with AIDS, although a substantial degree of sequence diversity was noticed. Here we examine the possibility that functional defects in Nef are responsible for the wellbeing of our long-term survivors.

To characterize nef functionally, we created chimeric viruses that contain nef derived from long-term survivors. Commonly, this process is accomplished by enzyme digestion and ligation (21). However, this technique is frequently hampered by a lack of appropriate recognition sites for restriction enzymes. Consequently, the reconstituted chimeras often contain undesired flanking sequences at both ends of the target gene, which could, in principle, alter the properties of the gene in an assay system. Here we report a new technique that allows the precise replacement of the nef of an infectious molecular clone, HIV$1_{\mathrm{HXB} 2}$, with alleles derived from study subjects without limita- 

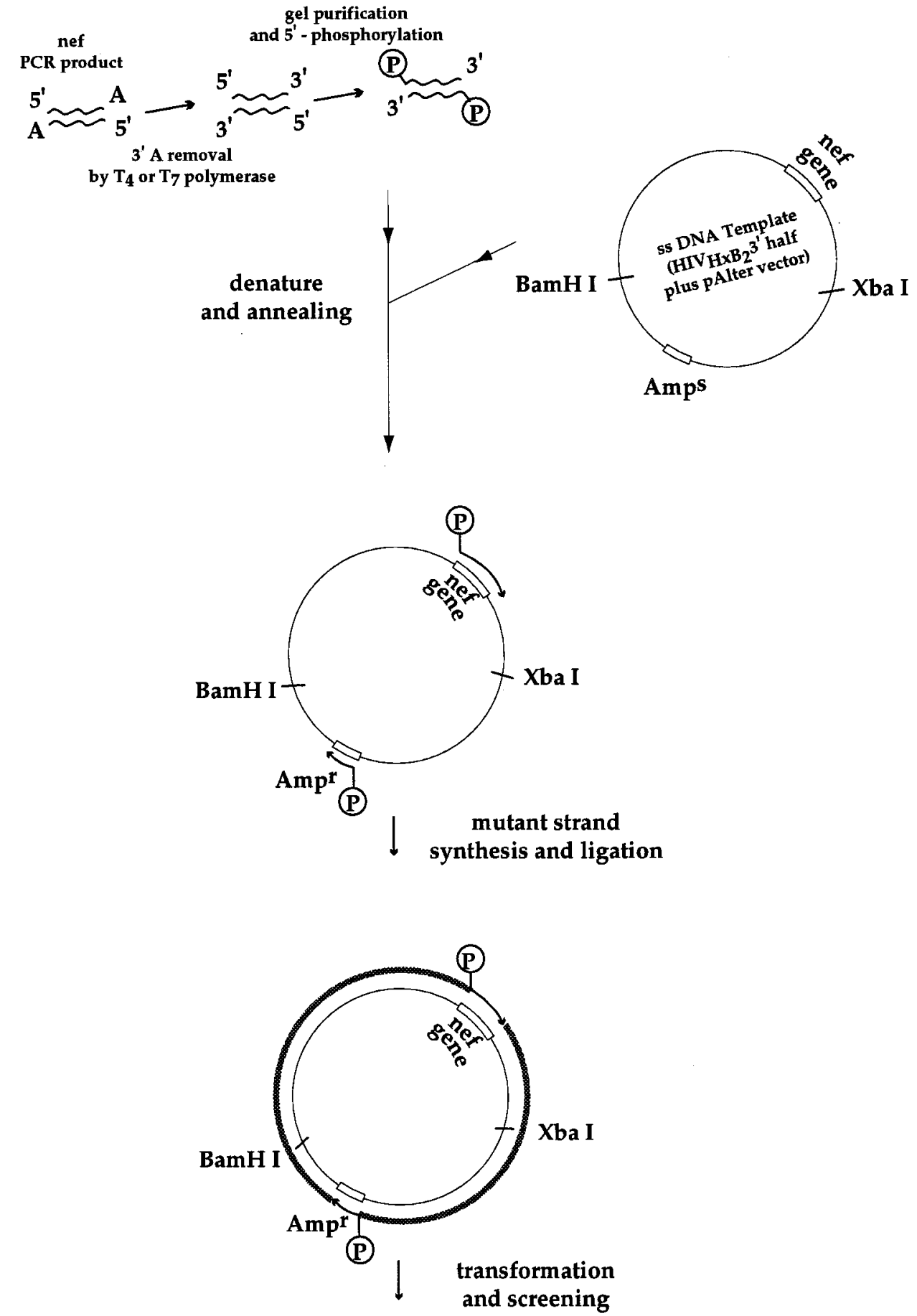

FIG. 1. Schematic diagram of the site-directed gene replacement procedure. Phagemid single-stranded DNA containing the $3^{\prime}$ half of the HIV-1 ${ }_{\mathrm{HXB} 2}$ genome (Bam HI-XbaI fragment) in the pAlter-1 vector was prepared by a standard polyethylene glycol-phenol procedure (Promega). HIV-1 nef (approximately 650 bp in length) was amplified by PCR $\left(94^{\circ} \mathrm{C}\right.$ for $1 \mathrm{~min}, 55^{\circ} \mathrm{C}$ for $1 \mathrm{~min}$, and $72^{\circ} \mathrm{C}$ for $1.5 \mathrm{~min}$ ) directly from a previously sequenced clone (10), with precise start and stop codons delineated by primers corresponding to individual nef sequences (see Fig. 2). Prior to its use in the mutagenesis reaction, the nef PCR product was treated with 10 to $12 \mathrm{U}$ of either T4 or T7 polymerase (New England Biolabs) in 5 to $7 \mathrm{mM} \mathrm{MgCl}$ (by adding an appropriate amount of $\mathrm{MgCl}_{2}$ directly to the PCR product) to remove the 3'-deoxyadenosine overhang that had been added nonspecifically by Taq polymerase during amplification (5). The modified nef PCR product was then gel purified by Geneclean (Bio 101) and 5' phosphorylated (50 mM Tris- $\mathrm{HCl}$ [pH 7.5], $10 \mathrm{mM} \mathrm{MgCl}_{2}, 5 \mathrm{mM}$ dithiothreitol, $0.1 \mathrm{mM}$ spermidine, $1 \mathrm{mM}$ ATP). Because of the inactivation of the ampicillin resistance gene in the single-stranded (ss) DNA template, the ampicillin repair oligonucleotide was added to restore the resistance phenotype; this subsequently served as a marker to screen mutants. This step was accomplished by annealing ampicillin repair primer to the ss DNA template simultaneously with the modified $n e f$ PCR product at $95^{\circ} \mathrm{C}$ for $5 \mathrm{~min}$, with subsequent gradual cooling to room temperature. Subsequent steps, including mutant-strand synthesis and ligation, transformation of competent bacteria, and preparation of plasmid DNA, were carried out according to the manufacturer's (Promega) instructions. 


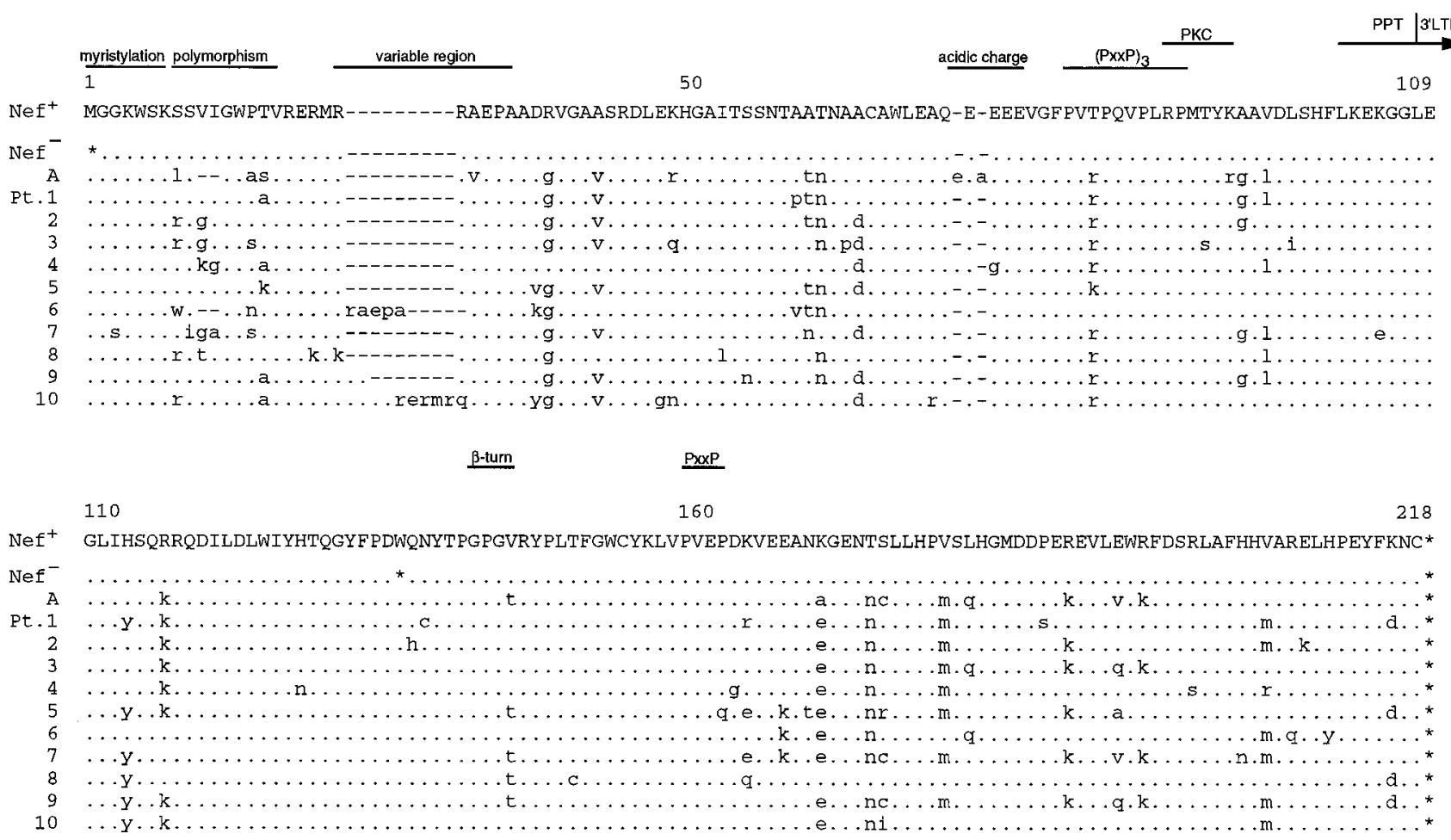

FIG. 2. Multiple sequence alignment and comparison of Nef protein sequences that were functionally characterized. Nef ${ }^{+}$, the nef sequence modified from $\mathrm{HIV}-1_{\mathrm{HXB} 2}$ to create an open reading frame; $\mathrm{Nef}^{-}$, the $\mathrm{HIV}-1_{\mathrm{HXB} 2}$ nef sequence containing a stop codon at position 1; A, sequence obtained from a patient with AIDS. Ten sequences derived from long-term survivors are listed for patients (Pt.) 1 to 10. -, gap introduced to maximize alignment; ., amino acid identity; *, stop codon. The locations of predicted motifs of the myristylation signal, sequence polymorphism, variable region, acidic charged residues, $(\mathrm{PXXP})_{3}$ repeat, putative phosphorylation site (PKC), polypurine tract (PPT) 5' border of the $3^{\prime}$ long terminal repeat (LTR), and $\beta$-turn are shown above the Nef protein sequences.

tions imposed by the need for restriction enzyme sites. This method, which we term site-directed gene replacement, relies primarily on the use of in vitro mutagenesis and PCR amplification techniques. The key feature of this method is that instead of short oligonucleotides, a denatured PCR product (confined to the exact region of interest by primers) is used as an initiation primer to perform mutant-strand synthesis and ligation, thereby controlling gene replacement to the level of a single nucleotide.

As illustrated in Fig. 1, modified PCR amplicons containing $n e f$ were denatured and annealed to the single-stranded DNA template containing the nef gene of the HIV-1 $1_{\mathrm{HXB} 2} 3^{\prime}$-BamHI$X b a \mathrm{I}$ fragment. Following mutant-strand synthesis and ligation, the mutated plasmids were transformed into competent bacteria. Screening for mutants with the nef sequence was carried out by direct double-stranded DNA sequencing with a Sequenase kit (United States Biochemical Corp.). Under these conditions, the gene replacement efficiency was approximately $23 \%$. The proviral chimeric construct was then generated by transferring the mutated BamHI-XbaI fragment of the HIV$1_{\mathrm{HXB} 2}$ genome, which contained the patient's nef allele, into the remaining $\mathrm{HIV}-1_{\mathrm{HXB} 2}$ background in the pBluescript vector. As controls, the $\mathrm{Nef}^{+} \mathrm{HIV}-1$ used in this study was a modification of the HXB2 molecular clone in which the premature stop codon at position 118 was opened by site-directed mutagenesis (stop $\rightarrow$ Trp), whereas $\mathrm{Nef}^{-}$HIV-1 was constructed by replacing the start codon of HXB2 nef with a stop codon ( $\mathrm{M} \rightarrow$ stop) (Fig. 2). In order to generate infectious viruses, $20 \mu \mathrm{g}$ of each plasmid construct was transfected into cells of the 293 line by calcium phosphate precipitation (21). Two days posttransfection, virus-containing supernatants were harvested, filtered through a $0.45-\mu \mathrm{m}$-pore-size filter, aliquoted, and frozen at $-70^{\circ} \mathrm{C}$. The p 24 concentrations in supernatants as determined by an antigen capture assay (Abbott Laboratories) were relatively high, ranging from 600 to 2,000 $\mathrm{ng} / \mathrm{ml}$. The numbers of virion-associated RNAs in supernatants were also determined by a quantitative, branched DNA signalamplification assay (Chiron Corp.). The amount of each virus used in subsequent experiments was normalized by these two parameters; the inocula were approximately $5 \mathrm{ng}$ of p24 antigen or about $1.7 \times 10^{4}$ HIV-1 RNA copies.

Although the precise function of nef is unknown, recent studies have shown a positive effect of nef on the rate of viral replication in primary peripheral blood mononuclear cells (PBMC) $(7,18,27,30)$ as well as in certain T-cell lines (4). To examine whether nef alleles derived from long-term survivors were capable of enhancing HIV-1 replication in vitro, we chose the predominant nef sequence from each of 10 long-term survivors (Fig. 2) and introduced these sequences into the infectious molecular clone HIV-1 ${ }_{\mathrm{HXB} 2}$. A nef gene derived from a patient with AIDS was also introduced into HXB2 as a control. We reasoned that the predominant sequence is more representative of a viral population in vivo than minor variants are. The replication kinetics of chimeric viruses were tested in phytohemagglutinin-stimulated PBMC and in initially resting PBMC that were activated by phytohemagglutinin 2 days postinfection. As shown in Fig. 3, the replication kinetics of viruses in initially resting PBMC were slightly slower than those in mitogen-preactivated PBMC. In both cases, $\mathrm{Nef}^{+}$ HIV $-1_{\text {HXB2 }}$ replicated more efficiently than Nef ${ }^{-}$HIV- $1_{\text {HXB2 }}$ did. The difference was more profound (approximately 100fold) in initially resting PBMC cultures (Fig. 3B), which is 

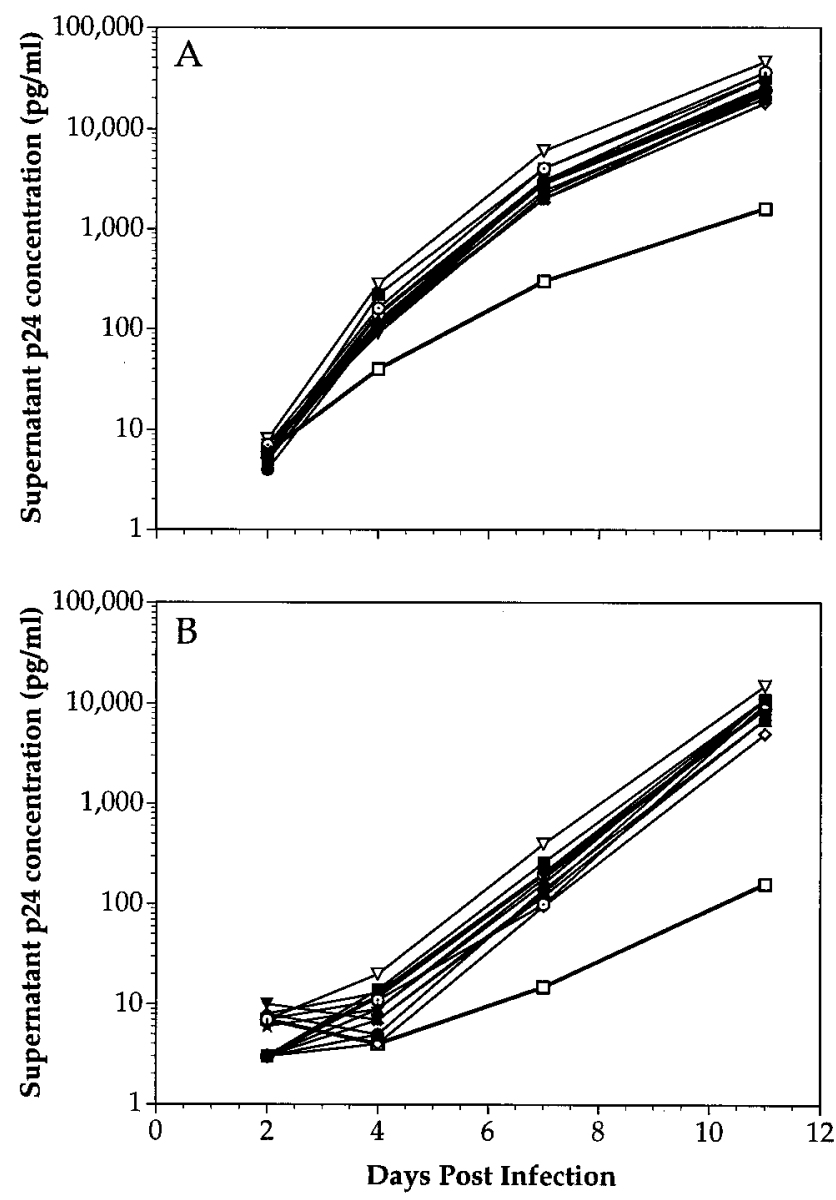

FIG. 3. The replication kinetics of chimeric viruses in comparison with those of $\mathrm{Nef}^{+} \mathrm{HIV}-1_{\mathrm{HXB} 2}$ and $\mathrm{Nef}^{-} \mathrm{HIV}-1_{\mathrm{HXB} 2}$. Primary PBMC were isolated from healthy donors by Ficoll-Hypaque (Pharmacia) gradient centrifugation. PBMC $\left(2 \times 10^{6}\right)$ were aliquoted on 24-well tissue culture plates in $1 \mathrm{ml}$ of culture medium (RPMI medium, $10 \%$ fetal calf serum [FCS]). Activated PBMC (A) were cultured in the presence of phytohemagglutinin $(2 \mu \mathrm{g} / \mathrm{ml})$ for 2 days. These stimulated cultures were then supplemented with interleukin-2 (IL-2; $15 \mathrm{U} / \mathrm{ml}$ ) and infected with HXB2-based chimeric viruses by the addition of the indicated viral stocks ( $5 \mathrm{ng}$ of p24 per ml) derived from transfections of cells from the 293 line. Six hours later, infected cultures were washed three times with RPMI and resuspended in $1 \mathrm{ml}$ of growth medium (RPMI, $10 \%$ FCS, $15 \mathrm{U}$ of IL-2 per ml). Alternatively, resting PBMC (B) were infected immediately after isolation by a similar addition of viral stocks for $6 \mathrm{~h}$, washed, and cultured in culture medium without stimulation. Two days later, these cells were activated by exchanging $50 \%$ of the culture medium for $2 \times$ phytohemagglutinin-IL- 2 medium (RPMI, $10 \% \mathrm{FCS}, 4 \mu \mathrm{g}$ of phytohemagglutinin per $\mathrm{ml}, 30 \mathrm{U}$ of IL-2 per ml). In both experiments, $50 \%$ of the culture supernatant from each well was collected for p24 assay on days 2, 4, 7, and 11 postinfection and replaced with fresh growth medium. $\bigcirc, \mathrm{Nef}^{+} \mathrm{HIV}_{-1} 1_{\mathrm{HXB} 2} ; \square, \mathrm{Nef}^{-} \mathrm{HIV}-1_{\mathrm{HXB} 2} ; \triangle$, patient A with AIDS; $\diamond$, patient $1 ; \boldsymbol{\ominus}$, patient 2 ; $\odot$, patient $3 ; \boldsymbol{\kappa}$, patient $4 ; \mathbf{\square}$, patient 5 ; $\boldsymbol{\Delta}$, patient 6 ; $\bullet$, patient $7 ; \star$, patient $8 ; \nabla$, patient $9 ; \boldsymbol{\nabla}$, patient 10 . The number codes of these subjects in the order listed here correspond to the letter codes (patients E, SF, LSS, RR, RP, BO, LM, DH, D, and CD) in reference 10. Datum points are the averages of duplicates and are representative of two experiments.

consistent with previous reports $(18,27)$. A comparison of the growth kinetics of the chimeric viruses carrying nef alleles derived from long-term survivors with that of the virus containing nef derived from a patient with AIDS revealed no obvious differences (Fig. 3). All chimeric viruses replicated with kinetics virtually identical to that of the parental $\mathrm{Nef}^{+}$ $\mathrm{HIV}-1_{\mathrm{HXB} 2}$. These results indicate that $n e f$ alleles derived from our long-term survivors can enhance viral replication in PBMC in vitro.
To further characterize the biological properties of nef alleles derived from long-term survivors, we utilized the singlecell infection assay (MAGI assay) developed by Kimpton and Emerman (12). In this assay, the infection of HeLa-CD4-LTR$\beta$-gal cells by HIV-1 induces Tat-dependent, long terminal repeat-driven $\beta$-galactosidase expression, thus causing infected cells to stain blue in the presence of X-Gal (5-bromo-4-chloro3 -indolyl- $\beta$-D-galactopyranoside) substrate. Thus, the infectivity of virus can be assessed at the single-cell level. As in replication kinetics assays, $5 \mathrm{ng}$ of p24 per well of viral supernatant was used to initiate each infection. In accordance with previous studies (18), we found that $\mathrm{Nef}^{+} \mathrm{HIV}-1_{\mathrm{HXB} 2}$ is approximately 10 -fold more infectious than $\mathrm{Nef}^{-} \mathrm{HIV}-1_{\mathrm{HXB} 2}$ in this assay (Fig. 4). The infectivities of chimeric viruses containing nef alleles derived from long-term survivors were comparable to that of $\mathrm{Nef}^{+} \mathrm{HIV}-1_{\mathrm{HXB} 2}$; all of these viruses infected more cells than $\mathrm{Nef}^{-} \mathrm{HIV}-1_{\mathrm{HXB} 2}$ did, ranging from 7.2-fold for nef from patient 4 to 14 -fold for nef from patient 9 . Similarly, a ninefold enhancement in infectivity was observed for a chimeric virus containing a nef allele from a patient with AIDS. These results suggest that nef alleles derived from long-term survivors are not inherently defective and can facilitate infection events leading to Tat production in the first round of infection.

By comparing the individual consensus Nef sequences of our study subjects with the consensus Nef sequence obtained by Shugars et al. (25) from patients with AIDS, we have previously shown that the sequences of proposed functional regions are highly conserved in most cases (10) (Fig. 2). A few changes were observed in specific regions; for instance, the consensus sequence of nef from patient 7 was found to have a glycine-toserine change in the second position of the N-terminal myristylation signal sequence (GGXXS) (Fig. 2). Changes from lysine to glutamine in the polypurine tract were also observed in nef from the same subject. However, the (PXXP) $)_{3}$ repeat sequence which resembles an SH3-binding site (19) is invariant. Another well-conserved (PXXP) SH3-binding motif close

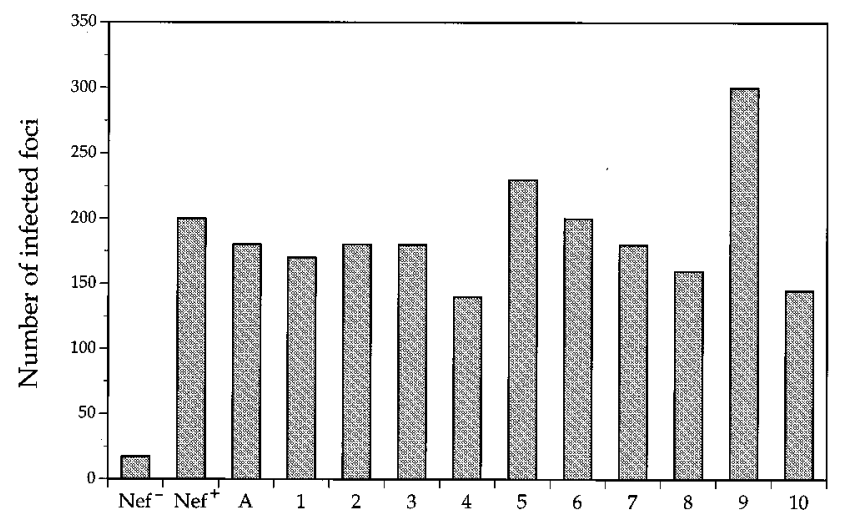

FIG. 4. The infectivities of chimeric viruses quantified by MAGI assay. HeLa-CD4-LTR- $\beta$-gal cells $\left(5 \times 10^{4}\right.$ per well $)$ were plated on 24 -well plates. One day after plating, culture medium (Dulbecco minimal essential medium, $10 \%$ FCS, $0.1 \mathrm{mg}$ of G418 per $\mathrm{ml}$ ) was removed and $200 \mu \mathrm{l}$ of virus (5 $\mathrm{ng}$ of p24) was added to each well. Two hours after infection, $1 \mathrm{ml}$ of culture medium was added to each well. Forty hours postinfection, cells were fixed with $1 \%$ formaldehyde- $0.2 \%$ glutaraldehyde in phosphate-buffered saline (PBS), washed twice with PBS, and incubated with the $\beta$-galactosidase substrate $\mathrm{X}-\mathrm{Gal}$. The number of infected, blue cells expressing Tat was scored by using a light microscope. Each cell division event over the infection period was counted as one infection event. Data are the averages of duplicate determinations. This experiment was repeated twice and verified by infecting cells with 10 and $20 \mathrm{ng}$ of p24 per well. The results indicate that data obtained by this assay are reproducible and linear over the range of 20 to 500 infected cells. 
to the $\mathrm{C}$ terminus was found to be replaced by PXXQ in nef from patient 5. Nevertheless, these changes do not seem to have a measurable impact on $n e f$-mediated viral replication and infectivity.

In summary, we have developed a site-directed gene replacement technique which allowed us to replace the nef gene of an infectious molecular clone, $\mathrm{HIV}-1_{\mathrm{HXB} 2}$, with nef alleles derived from 10 long-term survivors and from a patient with AIDS. We chose one predominant sequence from each subject and biologically characterized these nef alleles in the context of infectious virus. Our results demonstrated that the replication competencies of chimeric viruses containing nef alleles derived from long-term survivors were comparable to that of $\mathrm{Nef}^{+}$ $\mathrm{HIV}-1_{\mathrm{HXB} 2}$. Moreover, these chimeric viruses were always more infectious than $\mathrm{Nef}^{-} \mathrm{HIV}-1_{\mathrm{HXB} 2}$ was in a single-cell infection assay. Thus, we conclude that the genotypic and phenotypic features of nef are not likely to account for the nonprogression of HIV-1 infection in the 10 cases we studied, unless the function of the nef gene in vivo is not accurately reflected by the in vitro assays we used.

We thank Mary Ann Wiskerchen for technical assistance; C. ChengMayer, R. A. Koup, N. R. Landau, and J. P. Moore for critical reading of the manuscript; and Wen Chen for preparation of figures. HeLaCD4-LTR- $\beta$-gal was obtained through the AIDS Research and Reference Reagent Program, Division of AIDS, NIAID, NIH.

This work was supported by NIH grants AI24030, AI25541, AI32427, AI27665, AI27742 (Center for AIDS Research), and AI45218 (Correlates of HIV Immune Protection contract) and by the Aaron Diamond Foundation.

\section{REFERENCES}

1. Bacchetti, P., and A. R. Moss. 1989. Incubation period of AIDS in San Francisco. Nature (London) 338:251-253.

2. Buchbinder, S. P., D. Mann, L. Louie, F. Katz, and S. D. Holmberg. 1993. Healthy long-term positives (HLPs): genetic cofactors for delayed HIV disease progression, p. 46. In IX International Conference on AIDS.

3. Cao, Y., L. Qin, L. Zhang, J. Safrit, and D. D. Ho. 1995. Virologic and immunologic characterization of long-term survivors of human immunodeficiency virus type 1 infection. N. Engl. J. Med. 332:201-208.

4. Chowers, M. Y., C. A. Spina, T. J. Kwoh, N. J. S. Fitch, D. D. Richman, and J. C. Guatelli. 1994. Optimal infectivity in vitro of human immunodeficiency virus type 1 requires an intact nef gene. J. Virol. 68:2906-2914.

5. Clark, J. M. 1988. Novel non-templated nucleotide addition reactions catalyzed by procaryotic and eucaryotic DNA polymerase. Nucleic Acids Res. 16: 9677-9687.

6. Connor, R. I., H. Mohri, Y. Cao, and D. D. Ho. 1993. Increased viral burden and cytopathicity correlate temporally with CD4+ T-lymphocyte decline and clinical progression in human immunodeficiency virus type 1-infected individuals. J. Virol. 67:1772-1777.

7. deRonde, A., B. Klaver, W. Keulen, L. Smit, and J. Goudsmit. 1992. Natural nef accelerates virus replication in primary human lymphocytes. Virology 188:391-395.

8. Greenough, T. C., M. Somasundaran, D. B. Brettler, R. M. Hesselton, A. Alimenti, F. Kirchhoff, D. Panicali, and J. L. Sullivan. 1994. Normal immune function and inability to isolate virus in culture in an individual with longterm human immunodeficiency virus type 1 infection. AIDS Res. Hum. Retroviruses 10:395-403.

9. Ho, D. D., T. Moudgil, and M. Alam. 1989. Quantitation of human immunodeficiency virus type 1 in blood of infected persons. N. Engl. J. Med. 321: 1621-1625.

10. Huang, Y., L. Zhang, and D. D. Ho. 1995. Characterization of nef sequences in long-term survivors of human immunodeficiency virus type 1 infection. J. Virol. 69:93-100.
11. Kestler, H. W., D. J. Ringler, K. Mori, D. L. Panicali, P. K. Sehgal, M. D. Daniel, and R. C. Desrosiers. 1991. Importance of the nef gene for maintenance of high virus loads and/or development of AIDS. Cell 65:651-662.

12. Kimpton, J., and M. Emerman. 1992. Detection of replication-competent and pseudotyped human immunodeficiency virus with a sensitive cell line on the basis of activation of an integrated $\beta$-galactosidase gene. J. Virol. 66: 2232-2239.

13. Kirchhoff, F., T. C. Greenough, D. B. Brettler, J. L. Sullivan, and R. C. Desrosiers. 1995. Absence of intact nef sequences in a long-term survivor with nonprogressive HIV-1 infection. N. Engl. J. Med. 332:228-232.

14. Learmont, J., L. Cook, H. Dunckley, and J. S. Sullivan. 1995. Update on long-term symptomless HIV-1 infection in recipients of blood products from a single donor. AIDS Res. Hum. Retroviruses 11:1.

15. Learmont, J., B. Tindall, L. Evans, A. Cunningham, P. Cunningham, J. Wells, R. Penny, J. Kaldor, and D. A. Cooper. 1992. Long-term symptom-less HIV-1 infection in recipients of blood products from a single donor. Lancet 340:863-867.

16. Lifson, A. R., S. P. Buchbinder, H. W. Sheppard, A. C. Mawle, J. C. Wilber, M. Stanley, C. E. Hart, N. A. Hessol, and S. D. Holmberg. 1991. Long-term human immunodeficiency virus infection in asymptomatic homosexual and bisexual men with normal CD4+ lymphocyte counts: immunologic and virologic characteristics. J. Infect. Dis. 163:959-965.

17. McLean, K. A., D. A. Holmes, and B. A. Evans. 1990. Rapid clinical and laboratory progression of HIV-1 infection. AIDS 4:369-371.

18. Miller, M. D., M. T. Warmerdam, I. Gaston, W. C. Greene, and M. B. Feinberg. 1994. The human immunodeficiency virus-1 nef gene product: a positive factor for viral infection and replication in primary lymphocytes and macrophages. J. Exp. Med. 179:101-113.

19. Saksela, K., G. Cheng, and D. Baltimore. 1995. Proline-rich (PxxP) motifs in HIV-1 Nef bind to SH3 domains of a subset of Src kinases and are required for the enhanced growth of Nef+ viruses but not for down-regulation of CD4. EMBO J. 14:484-491.

20. Saksela, K., C. Stevens, P. Rubinstein, and D. Baltimore. 1994. Human immunodeficiency virus type $1 \mathrm{mRNA}$ expression in peripheral blood cells predicts disease progression independently of the numbers of CD4+ lymphocytes. Proc. Natl. Acad. Sci. USA 91:1104-1108.

21. Sambrook, J., E. F. Fritsch, and T. Maniatis. 1989. Molecular cloning: laboratory manual, 2nd ed. Cold Spring Harbor Laboratory Press, Cold Spring Harbor, N.Y.

22. Schnittman, S. M., J. J. Greenhouse, M. C. Psallidopoulos, M. Baseler, N. P. Salzman, A. S. Fauci, and H. C. Lane. 1990. Increased viral burden in CD4+ $\mathrm{T}$ cell from patients with human immunodeficiency virus (HIV) infection reflects rapidly progressive immunosuppression and clinical disease. Ann. Intern. Med. 113:438-443.

23. Schrager, L. K., J. M. Young, M. G. Fowler, B. J. Mathieson, and S. H Vermund. 1994. Long-term survivors of HIV-1 infection: definition and research challenges. AIDS 8(Suppl. 1):S95-S108.

24. Sheppard, H. W., W. Lang, M. S. Ascher, E. Vittinghoff, and W. Winkelstein 1993. The characterization of non-progressor: long-term HIV-1 infection with stable CD4+ T-cell levels. AIDS 7:1159-1166.

25. Shugars, D. C., M. S. Smith, D. H. Glueck, P. V. Nantermet, F. SeillierMoiseiwitsch, and R. Swanstrom. 1993. Analysis of human immunodeficiency virus type 1 nef gene sequences present in vivo. J. Virol. 67:4639-4650. (Author's correction, 68:5335, 1994.)

26. Simmonds, P., P. Balfe, L. F. Peutherer, C. A. Ludlam, J. O. Bishop, and A. J. Leigh Brown. 1990. Human immunodeficiency virus-infected individuals contain provirus in small numbers of peripheral mononuclear cells and at low copy numbers. J. Virol. 64:864-872.

27. Spina, C. A., T. J. Kwoh, M. Y. Chowers, J. C. Guatelli, and D. D. Richman. 1994. The importance of nef in the induction of human immunodeficiency virus type 1 replication from primary quiescent CD4 lymphocytes. J. Exp. Med. 179:115-123.

28. Tersmette, M., R. A. Gruters, F. de Wolf, R. E. Y. de Goede, J. M. A. Lange, P. T. A. Schellekens, J. Goudsmit, H. G. Huisman, and F. Miedema. 1989. Evidence for a role of virulent human immunodeficiency virus (HIV) variants in the pathogenesis of acquired immunodeficiency syndrome: studies on sequential HIV isolates. J. Virol. 63:2118-2125.

29. Weiss, R. A. 1993. How does HIV cause AIDS? Science 260:1273-1279.

30. Zazopoulos, E., and W. A. Haseltine. 1993. Effect of nef alleles on replication of human immunodeficiency virus type 1. Virology 194:20-27. 